\title{
Prevalence of depression in patients with chronic obstructive pulmonary disease: a systematic review
}

\author{
L van Ede, C J Yzermans, H J Brouwer
}

\begin{abstract}
Background-Patients with chronic obstructive pulmonary disease (COPD) have repeatedly been characterised as a population of chronically ill patients with a higher than normal prevalence of depression. Susceptibility for depression has been noted in patients with certain other chronic conditions. This systematic review was conducted to achieve a more definite answer to the question: do patients with COPD show a higher than normal prevalence of depression?

Methods-Studies in English language journals were retrieved by an electronic search over the period from 1966 to December 1997 and by an extended search of reference lists, and were included or excluded according to a system of diagnostic and methodological criteria.

Results-Ten studies were included, of which only four had a case-control design. Three of the case-control studies reported an increased prevalence of depression among patients with COPD which was statistically significant in only one. The fourth controlled study found a significantly increased depression score among COPD patients. Of the remaining six uncontrolled studies three found a high baseline prevalence of depression among their study group.
\end{abstract}

Conclusions-An association between COPD and depression was found in the four controlled studies. The two methodologically best conducted studies that did not detect a statistically significant higher prevalence lacked power. The two studies that did find a significant association used a questionable depression measure. The prevalence of depression was high compared with general population figures in three of six non-controlled studies. The empirical evidence for a significant risk of depression in patients with COPD remains inconclusive, due to the poor methodological quality of most of the published studies, the lack of studies with an adequate sample size, and variability in instruments and cut off scores used to measure depression.

(Thorax 1999;54:688-692)

Keywords: chronic obstructive pulmonary disease; depression; review
Patients with chronic airway problems form an important population in primary care. Chronic obstructive pulmonary disease (COPD) is a term for a group of chronic lung disorders, especially chronic obstructive bronchitis and emphysema, mostly characterised by a slowly progressive irreversible bronchial obstruction (expressed in a progressive limitation of the forced expiratory volume in one second $\left.\left(\mathrm{FEV}_{1}\right)\right)$ and a fluctuating symptom complex of recurrent productive cough and dyspnoea. ${ }^{1-3}$ Eighty percent of the medical care for these patients in the Netherlands is provided by the general practitioner. ${ }^{4}$ Caring for the chronically ill in primary care is a challenging task for the general practitioner; the most important task is not cure but optimising the quality of life of the individual patient.

The quality of life of a chronically ill patient may be particularly complicated by a concurrent depressive disorder, which may bring the patient into a vicious circle: the depressed mood lowers the force needed to cope with the chronic disease, the physical symptoms become less tolerable, and the psychosocially debilitating effect of the disease may be enforced by the depressed mood. Mislabelling depressive symptoms as side effects of COPD might lead to underdetection and undertreatment in general practice. Intrinsic pulmonary causative mechanisms might be the debilitating sequelae of chronic dyspnoea and diminished exercise tolerance. ${ }^{5}$ Finally, frequent steroid use might cause or worsen depression as an adverse effect.

How likely is the development of depression in patients with COPD? Several nonsystematic overviews of the literature on this subject have been published, ${ }^{5-10}$ in all of which a high prevalence of depression has been described. The present review was conducted to answer the following question: do patients with COPD show a higher prevalence of depression than those who do not suffer from COPD?

\section{Methods}

ASSESSMENT OF COPD AND DEPRESSION

There is still a lack of uniformity on the objective characteristics and test results of COPD. A clinical diagnosis and the $\mathrm{FEV}_{1}$ value are the minimum requirements for a study to be considered valid. ${ }^{1}$ The $\mathrm{FEV}_{1}$ is an indicator of the severity of bronchial obstruction; the best way to present and interpret this value is as a percentage of the optimal value calculated for the individual's age, height, sex, and race. ${ }^{211}$ 
Table 1 Criteria and scoring system for assessment of study methodology

\begin{tabular}{ll}
\hline Criterion & Score \\
\hline Random selection of patients & 1 \\
Control group matched for age and sex & 2 \\
Response rate $>80 \%$ & 1 \\
Prevalence of depressive disorder detectable & 1 \\
Exclusion of important physical disease other than & \\
$\quad$ COPD & 1 \\
Maximum score & 6 \\
\hline
\end{tabular}

Caution is needed with the interpretation of spirometric values because the results are influenced by the patient's cooperation. In patients with COPD the $\mathrm{FEV}_{1}$ is $<75 \%$ of the predicted value; an $\mathrm{FEV}_{1}$ of $60-70 \%$ of the predicted value is indicative of moderate bronchial obstruction and an $\mathrm{FEV}_{1}$ of $<50 \%$ of the predicted value or $<1.5 \mathrm{l} / \mathrm{s}$ indicates severe bronchial obstruction. ${ }^{12}$

In this review the term "depression" is used to indicate a significant depressive disorder and not a temporarily depressed mood. In research depression is usually detected by using one of three types of measures: self-report questionnaires, checklist based structured interviews, and clinical assessment by a psychiatrist. The latter, based on DSM-III-R standards, is often used as the golden standard in validation studies of the first two measures. The self-report instruments are most often used because they are quick and inexpensive. The cut off values of the rating scales are usually calculated to detect a depressive disorder. When structured interviews or clinical assessments are used, DSM criteria are usually applied to identify a depressive disorder.

SELECTION OF STUDIES

All relevant studies published since 1966 (the starting year for Medline) were retrieved from the literature data bases as well as from the reference lists of the resulting articles. The electronic search was undertaken with the OVID search program using the following terms: "Exp Lung diseases, obstructive" or "COPD.tw" and "Exp Depressive disorder" or "Depression.tw" or "Exp affective disorder". The period 1966-1997 was covered by Medline, 1988-1997 was covered by Embase, and 1982-1997 was covered by CINAHL. All studies dealing with depression in patients with COPD were selected for further evaluation.

Overall, 393 abstracts were read. Excluded were studies on patients with bronchial asthma ( $\mathrm{n}=128$ ), clinical trials of antidepressive medication (where patients were included because of a depressive disorder), studies on

Table 2 Validated assessment tools for depression used in retrieved studies

BDI (Beck depression inventory) ${ }^{15}$; originally advised interpretation: $0-4$ no depression, 5-13 mild depression, 14-20 moderate depression, $>21$ severe depression, maximum score 63 Zung SDS (Zung self-rating depression scale) $)^{16}$; originally advised interpretation: $<50$ no depression, 50-59 mild depression, 60-69 moderate depression, $>69$ severe depression, maximum score 80

HAD (Hospital anxiety and depression questionnaire) ${ }^{17}$; originally advised interpretation: $<7$ no depression, $8-10$ possible depression, $>10$ certain depression, maximum depression score 21 CES-D (Center for epidemiologic studies-depression questionnaire) ${ }^{18}$; originally advised interpretation: cut off score for depression 16, maximum score 60

MMPI (Minnesota multiphasic personality inventory) ${ }^{19}$; interpretation: normal $t$ score per field 50 ; interpretation for mood disorder is hazardous because of large amount and heterogeneity of items. the prevalence of anxiety disorders $(n=89)$, animal experiments $(\mathrm{n}=7)$, and studies published in a language other than English $(\mathrm{n}=$ 48). Furthermore, 56 reviews, case descriptions, and letters to the editor without original research results were excluded from our review. A further 16 studies were identified from the reference lists of the selected publications, four of which were also included in the review.

The remaining 69 studies were rated by the three authors on three sets of criteria chosen in several sessions: the assessment of COPD, the method used to detect depression, and the methodology applied. The first two sets (on COPD and depression) were applied as entry criteria; studies that failed to meet one of these were excluded. The COPD criteria were checked by an expert opinion (senior pulmonologist): a clinical diagnosis in combination with the mean value of the $\mathrm{FEV}_{1}$, preferably expressed as a percentage of the predicted value. The severity of the disease in the sample can be estimated from the mean $\mathrm{FEV}_{1}$ (table $1)$.

To detect depression most of the retrieved studies used a self-rating measuring instrument and some used a clinical interview. A clinical interview by a psychiatrist based on DSM-III (or later versions) was considered an acceptable method. ${ }^{13}$ Self-rating instruments were considered acceptable if they had been validated in earlier studies. Bowling's book ${ }^{14}$ on measuring instruments was used as a guide to check this; the instruments used in the studies finally selected have all been validated in earlier studies (table 2). ${ }^{15-19}$ From the 69 studies thus judged, 35 failed to meet the criteria on COPD or depression and were excluded.

The methodology of the 34 remaining studies was assessed using a scoring system. Five methodological criteria were considered important: a case-control design with controls matched for age and sex, preferably random selection of patients in both groups, the exclusion of important physical co-morbidity in the studied COPD patients, a response rate of $80 \%$ or more, ${ }^{20}{ }^{21}$ and the availability of (or possibility to calculate) a prevalence rate for depression. Each criterion merited one point. Direct comparison in one design between a group of COPD patients and controls without the disease was considered of vital importance and therefore awarded an extra point.

The 34 studies were scored by each reviewer independently using the scoring system from table 1. Differences in scores between the three reviewers were resolved as follows: when two reviewers agreed, their score was taken as the final score. When all three reviewers disagreed, the article was jointly reviewed again and discussed until agreement was reached between at least two reviewers.

Studies with a methodology score of less than two points were excluded. One study ${ }^{22}$ was excluded because the population under study had already been used in an earlier study included by us. ${ }^{23}$ Finally, 10 studies were considered for final reviewing (table 3$)^{23-32}$ 
Table 3 Studies with prevalence of depressive disorders

\begin{tabular}{|c|c|c|c|c|c|c|c|c|}
\hline Reference & $\begin{array}{l}\text { No. of patients } \\
\text { (\% males) }\end{array}$ & $\begin{array}{l}\text { Age } \\
\text { (mean) }\end{array}$ & Recruitment of patients & $\begin{array}{l}\text { Mean } \\
F E V_{1}\end{array}$ & $\begin{array}{l}F E V_{1} \\
(\%)^{c}\end{array}$ & $\begin{array}{l}\text { No. of } \\
\text { controls (\% } \\
\text { males) }\end{array}$ & Age (mean) & Recruitment of controls \\
\hline Engström ${ }^{24}$ & $68(65 \%)$ & 65 & $\begin{array}{l}\text { Outpatient pulmonary } \\
\text { clinic }\end{array}$ & & $39.9 \%$ & $89(56 \%)$ & 63 & $\begin{array}{l}\text { Subsample recruited by } \\
\text { telephone from random } \\
\text { sample of Göteborg } \\
\text { citizens matched for age } \\
\text { and sex distribution }\end{array}$ \\
\hline Isoaho $^{25 a}$ & $82(75 \%)$ & 72 & $\begin{array}{l}\text { Community sample (Lieto } \\
\text { residents born in or before } \\
1926 \text { ) }\end{array}$ & & $<66 \%^{\mathrm{d}}$ & $246(74 \%)$ & Matched & $\begin{array}{l}\text { Three matched subjects } \\
\text { without respiratory } \\
\text { symptoms for each patient } \\
\text { from same community }\end{array}$ \\
\hline McSweeney $^{26}$ & $203(79 \%)$ & 66 & $\begin{array}{l}\text { Patients enrolled in } \\
\text { nocturnal oxygen } \\
\text { treatment trial }\end{array}$ & $0.75 \mathrm{l} / \mathrm{s}$ & & $73(76 \%)$ & 65 & $\begin{array}{l}\text { Healthy individuals } \\
\text { matched with subsample } \\
\text { of patient group }\end{array}$ \\
\hline Prigatano $^{27}$ & $89(79 \%)$ & 61 & $\begin{array}{l}\text { Patients enrolled in } \\
\text { intermittent positive } \\
\text { pressure breathing trial }\end{array}$ & & $36 \%$ & $24(84 \%)$ & 60 & $\begin{array}{l}\text { Healthy individuals } \\
\text { matched }{ }^{\mathrm{f}} \text { with subsample } \\
\text { of patient group }\end{array}$ \\
\hline Toshima $^{23}$ & $119(73 \%)$ & 63 & $\begin{array}{l}\text { Patients enrolled in } \\
\text { rehabilitation programme }\end{array}$ & & & & & \\
\hline Light $^{28}$ & $45(100 \%)$ & 63 & $\begin{array}{l}\text { Outpatient pulmonary } \\
\text { clinic }\end{array}$ & & $29 \%$ & & & \\
\hline Karajgi $^{32 b}$ & $50(62 \%)$ & 65 & $\begin{array}{l}\text { Outpatient pulmonary } \\
\text { clinic }\end{array}$ & & & & & \\
\hline Gordon $^{31}$ & $13(100 \%)$ & 63 & $\begin{array}{l}\text { Outpatient pulmonary } \\
\text { clinic }\end{array}$ & $0.70 \mathrm{l} / \mathrm{s}$ & & & & \\
\hline Jones $^{30}$ & $141(65 \%)$ & 63 & $\begin{array}{l}\text { Outpatient pulmonary } \\
\text { clinic }\end{array}$ & & $47 \%$ & & & \\
\hline Yellowlees $^{29}$ & $50(64 \%)$ & 65 & $\begin{array}{l}\text { Patients admitted with } \\
\text { exacerbation }\end{array}$ & $1.1 \mathrm{l} / \mathrm{s}$ & & & & \\
\hline
\end{tabular}

${ }^{\mathrm{a}}$ For each subject the $\mathrm{FEV}_{1} / \mathrm{FVC}$ value was determined, no clinical diagnosis of COPD was established.

${ }^{\mathrm{b}} \mathrm{No} \mathrm{FEV}_{1}$ value given, though a clinical diagnosis and chronic irreversible airflow obstruction is described.

${ }^{\mathrm{C}} \mathrm{FEV}_{1}$ expressed as \% of predicted value.

${ }^{\mathrm{d}} \mathrm{FEV}_{1} / \mathrm{FVC}$ expressed as $\%$ of predicted value.

${ }^{\mathrm{e}}$ Matched for age, sex, race, education, and socioeconomic status.

${ }^{\mathrm{f}}$ Matched for age, sex and education.

${ }^{\text {gRange } 0-6 .}$

${ }^{\text {h} P o s t ~ h o c ~ p o w e r ~ c a l c u l a t e d ~ u s i n g ~ t h e ~ n Q u e r y ~ A d v i s o r ~ p r o g r a m ~(s e c o n d ~ v e r s i o n), ~ g i v e n ~} \alpha=0.05$, using a two tailed test.

\section{Results}

Only four studies used a case-control design to compare results between patients with COPD and a control group. ${ }^{24-27}$ All of these detected a higher prevalence of depression among COPD patients than among controls, but in the two best rated studies ${ }^{24}{ }^{25}$ (with equal points for methodology) the differences were not statistically significant. One study, conducted on a sample of patients with severe COPD, ${ }^{24}$ found a difference in depression prevalence of $6 \%$ between patients and controls $(7 \%$ in patients and $1 \%$ in controls); the other study ${ }^{25}$ conducted on a community sample of patients with an $\mathrm{FEV}_{1} / \mathrm{FVC}$ of less than $66 \%$ of the predicted value found a difference of $9 \%(28 \%$ in patients and $19 \%$ in controls). The severity of COPD cannot be detected as no mean $\mathrm{FEV}_{1}$ is given but it is probably in the mild to moderate range as it was conducted on a community sample. The two case-control studies where a statistically significant difference was found ${ }^{26} 27$ used patients with severe COPD (both with a long term oxygen treatment indication). To estimate whether the controlled studies had adequate sample sizes a post hoc power was calculated on the difference in prevalences of depression found in the study using the nQuery Advisor 2.0 program. For one study ${ }^{27}$ this calculation was not possible because only the mean $t$ scores were reported without standard deviations. This also applies to the remaining six studies ${ }^{23}$ 28-32 which all lacked a control group. The (baseline) depression prevalences among the COPD patients in these studies lie within the range of $6-42 \%$; in five of these the prevalence was reported to be $12 \%$ or higher.
One of these studies ${ }^{28}$ was a rehabilitation trial on patients with COPD and the combined baseline data of the study and control groups were included in the review.

The majority of the studies described patient groups with moderate to severe COPD $\left(\mathrm{FEV}_{1}\right.$ $<50 \%$ or $<1.5 \mathrm{l} / \mathrm{s}$ ); only one study ${ }^{25}$ described patients with mild to moderate COPD.

\section{Discussion}

The methodologically best rated studies ${ }^{24} 25$ in this review did not find a statistically significant difference in the prevalence of depression between patients with COPD and controls.

The prevalence of depression (using the Hospital Anxiety and Depression (HAD) scale) in the study on Swedish subjects ${ }^{24}$ was strikingly low in both patients with severe COPD and controls compared with the prevalences found in the other studies. The difference between patients and controls was 6\% which was not statistically significant. Calculation of the post hoc power, however, revealed that the study sample was too small. In fact, 141 patients with COPD would have been needed to reach a power of $80 \%$ (which is the minimum required value ${ }^{20}$ ).

The only study using a community sample, a study on Finnish subjects, ${ }^{25}$ found a relatively high prevalence of depression (using the Zung SDS) in both patients and controls. Among the healthy controls the prevalence (19\%) was much higher than that found in the controls in the Swedish study. The difference detected between patients and controls was $9 \%$, which was not statistically significant. Post hoc power calculation revealed that this study, like the 
Table 3 continued

\begin{tabular}{|c|c|c|c|c|}
\hline \multirow{2}{*}{$\begin{array}{l}\text { Depression diagnosis } \\
\text { (cut off score) }\end{array}$} & \multirow{2}{*}{$\begin{array}{l}\text { Methodology } \\
\text { score }^{g}\end{array}$} & \multicolumn{2}{|c|}{ Prevalence of depression } & \multirow{2}{*}{$\begin{array}{l}\text { Post hoc power } \\
\text { calculation }^{h}\end{array}$} \\
\hline & & Patients & Controls & \\
\hline $\mathrm{HAD}(\geqslant 11)$ & 5 & $7 \%$ & $1 \%(\mathrm{NS})$ & $51 \%$ \\
\hline Zung SDS $(\geqslant 45)$ & 5 & $28 \%$ & $19 \%$ (NS) & $40 \%$ \\
\hline MMPI & 3 & $42 \%$ & $9 \%(\mathrm{p}<0.05)$ & $99 \%$ \\
\hline MMPI & 3 & $t$ score 70 & $\begin{array}{l}t \text { score } 59 \\
(\mathrm{p}<0.05)\end{array}$ & \\
\hline CES-D $(\geqslant 19)$ & $\begin{array}{l}3 \\
3\end{array}$ & $\begin{array}{l}29.4 \% \\
42 \%\end{array}$ & & \\
\hline $\mathrm{BDI}(\geqslant 15)$ & & & & \\
\hline SCI/DSM III-R & $\begin{array}{l}3 \\
2\end{array}$ & $\begin{array}{l}6 \% \text { (major) } \\
\text { BDI } 31 \% \text { (mild) }\end{array}$ & & \\
\hline $\begin{array}{l}\text { BDI }(\geqslant 15) \text {, Zung } \\
\text { SDS }(>44)\end{array}$ & & SDS $8 \%$ & & \\
\hline $\mathrm{HAD}(\geqslant 8)$ & 2 & $29 \%$ & & \\
\hline Interview (DSM-III) & 2 & $12 \%$ & & \\
\hline
\end{tabular}

Swedish one, was too small to detect a clinically relevant and statistically significant difference of $9 \%$; to reach a power of $80 \% 229$ patients needed to have been included. In accounting for the differences between the two studies the main attention should focus on the instruments used to measure depression and the cut off values chosen. The HAD scale has the advantage of being rather insensitive to age ${ }^{33}$ and to somatic symptoms. ${ }^{17}$ The use of the Zung SDS in the Finnish study in which the patients were on average older than in the Swedish study (72 years versus 65 years) could thus have resulted in higher prevalences, although by itself this is unlikely to explain the large differences found between the two studies. In the Swedish study a rather high cut off value of $\geqslant 11$ was applied to the HAD scale scores, which has been shown to have a low sensitivity $(50 \%)$ for detection of clinically relevant depression in a validation study on general medical outpatients. ${ }^{33}$ In a study on elderly stroke patients a lower cut off score of $\geqslant 5$ was reported to be optimal, giving a sensitivity of $83 \% .^{34}$ The cut off value chosen for the Zung SDS in the Finnish study was shown to have acceptable sensitivity (76\%) in a group of elderly stroke patients. ${ }^{16}$ The high cut off value in the Swedish study could have resulted in a lower prevalence at the same time of more severe depressive disorders.

The other two controlled studies, which were concluded to be of lesser methodological quality, were conducted on patients with severe COPD who were reported to be statistically significantly more depressed than healthy controls. ${ }^{26}{ }^{27}$ In one of these studies ${ }^{26}$ the preva- lence of depression was much higher in patients with COPD than in controls $(42 \%$ versus $9 \%$ ). The post hoc power calculated for this study was excellent (99\%). However, the quality of the depression instrument (MMPI) has been questioned; although widely used it is considered to be outmoded and has not been cross-validated with DSM-III criteria. Moreover, no cut off scores have been described, only $t$ scores which indicate the probability of belonging to a group of subjects with a certain disorder. ${ }^{19}$

The study by Prigatano et $a l^{27}$ reported higher $t$ scores for patients with COPD than for controls using the MMPI depression scale. Because no standard deviation of these scores was reported, the post hoc power could not be calculated. An indication of the relative credibility of this study may be that it included slightly more patients with COPD $(n=89)$ than the underpowered Finnish study but a much smaller group of controls $(n=24)$.

In the two studies using community samples the controls were matched only for age and $\mathrm{sex}^{24}{ }^{25}$ whereas in the other two studies the matching variables included education and social class. ${ }^{26}{ }^{27}$ Not taking into account the possible confounding effect of variables which are clearly related to COPD as well as to depression could result in the association between the two being obscured. Whether this is the case for education or social class is as yet not certain.

In summary, apart from the difference in nationality of the populations from which the samples were drawn, the striking difference between the prevalence of depression among the controls of the first three controlled studies $^{24-26}$ seems to be caused by two factors: the depression instrument and the cut off score used to detect the depressive disorder.

The empirical evidence for a significant risk of depression in patients with COPD is thus inconclusive. Possibly the most striking result of this review has been the observation of the poor quality of most studies. Only four studies satisfied what seems an absolute minimum requirement: a case-control design.

What about the other studies? Three out of the six studies ${ }^{23} 2830$ reported a prevalence of around $30 \%$ which is substantially higher than the prevalence in the general adult population as reported in recent large community surveys. The "past 12 month" prevalence of a major depressive episode among persons aged 15-54 years was found to be $10.3 \%$ in the USA ${ }^{35}$ and $5.8 \%$ in those aged 18-64 years in the Netherlands. ${ }^{36}$ The comparison of these figures is, of course, limited as patients with COPD belong to an older age group which was not included in these surveys. Because of the inconsistent results of the best quality studies it is impossible to attribute reported depression levels to the presence of COPD, to the length of the illness, to a chronic illness per se, or to the age group.

The occurrence of depression in association with medical illness has been studied particularly for cardiovascular diseases, stroke and several other neurological diseases, diabetes, 
and hypertension. ${ }^{37} 38$ These studies have shown that, before constructing any aetiological model, it is important to consider confounding explanations of an association. The most important confounder is an artefact of depression measurement due to an overlap between symptoms of the somatic illness and those considered indicative of depression. The Geriatric Depression Scale (GDS) ${ }^{5}$ and the HAD questionnaire ${ }^{14}$ are examples of instruments developed to counter this problem. Depression may also be a temporary adjustment as a result of the diagnosis of a potentially life threatening disease or a side effect of the medication used to treat the somatic illness (like corticosteroids). Unlike the disorders mentioned above, the occurrence of depression in association with COPD has not been adequately studied.

In conclusion, an association between COPD and depression was found in the four controlled studies reviewed. In the two studies $^{24} 25$ in which the better measuring instruments (HAD scale and Zung SDS) were used the association was not statistically significant, although the studies lacked power. The only controlled study that did have enough power detected a statistically significant relationship, but used a questionable depression measure without a certain cut off score (MMPI). Three of the six remaining studies included in our review did find a higher than normal prevalence of depression but the methodology of these studies was of much poorer quality and the results are therefore dubious.

Based on the current literature the association between COPD and depression has been neither proved nor rejected. In order to detect a clinically relevant association between COPD and depression, studies are needed that have a good methodological design, sufficient power, and use of a depression measure specifically validated for patients with COPD.

1 American Thoracic Society. Standards for the diagnosis and care of patients with chronic obstructive pulmonary disease and asthma. Am Rev Respir Dis 1987;136:225-31.

2 American Thoracic Society. Standardization of spirometry: 1987 update. Am Rev Respir Dis 1987;136:1285-98.

3 Petty TL. Chronic obstructive pulmonary disease. In: Petty TL. Chronic obstructive pulmonary disease. In:
Kelley WN, DeVita VT, et al, eds. Textbook of internal mediKelley WN, DeVita VT, et al, eds. Textbook of internal medi-
cine. 2nd ed. Philadelphia: J B Lippincott Company, 1992: cine. 2nd ed. $1717-21$.

4 Bottema BJAM. Diagnostiek van CARA in de huisartspraktijk. Dissertation, Amsterdam, 1993.

5 Dudley DL, Glaser EM, Jorgenson BN, et al. Psychosocial concomitants to rehabilitation in chronic obstructive pulmonary disease. Part I. Psychosocial and psychological considerations. Chest 1980;77:413-20.

6 Gift AG, McCrone SH. Depression in patients with COPD. Heart Lung 1993;22:289-97.

7 Dudley DL, Glaser EM, Jorgenson BN, et al. Psychosocial concomitants to rehabilitation in chronic obstructive pulmonary disease. Part II. Psychosocial treatment. Chest 1980;77:544-51.

8 Greenberg G, Ryan J, Bourlier P. Psychological and neuropsychological aspects of COPD. Psychosomatics 1985;26: 29-33.

9 Sandhu H. Psychosocial issues in chronic obstructive Sandhu H. Psychosocial issues in chronic obstruc
pulmonary disease. Clin Chest Med 1986;7:629-42.

10 Williams SJ. Chronic respiratory illness and disability: a critical review of the psychosocial literature. Soc Sci Med 1989;28:791-803.
11 Quanjer PH, Tammeling GJ, Cotes JE, et al. Standardized lung function testing. Official statement of the European Respiratory Society. Eur Respir f 1993;6:25-30.

12 Burrows B. Differential diagnosis of chronic obstructive pulmonary disease. Chest 1990;97(Suppl):16-18S.

13 American Psychiatric Association (APA). Quick reference to the diagnostic criteria from DSM-IV (Dutch translation). Lisse: Swets \& Zeitlinger BV, 1995: 203-44.

14 Bowling A. Measuring disease. Buckingham: Open University Press, 1995: 72-84, 152-53, 238-39.

15 Beck AJ, Steer RA, Garbin MG. Psychometric properties of the Beck Depression Inventory: twenty-five years of evaluation. Clin Psychol Rev 1988;8:77-100.

16 Agrell B, Dehlin O. Comparison of six depression rating scales in geriatric stroke patients. Stroke 1989;20:1190-4.

17 Wilkinson MJB, Barczak P. Psychiatric screening in general practice: comparison of the general health questionnaire and the hospital anxiety depression scale. $\mathcal{F} R$ Coll Gen Pract 1988,38:311-3.

18 Radloff LS. The CES-D scale: a self-report depression scale for research in the general population. Appl Psychol Measurement 1977;1:385-401.

19 Helmes E, Reddon JR. A perspective on developments in assessing psychopathology: a critical review of the MMPI and MMPI-2. Psychol Bull 1993;113:453-71.

20 Altman DG. Practical statistics for medical research. London: Chapman \& Hall, 1991: 440-99.

21 Mulrow CD, Oxman AD, eds. Cochrane Collaboration Handbook. Available in the Cochrane library. The Cochrane Collaboration; Issue 1. Oxford: Update Software, 1997.

22 Ries A, Kaplan R, Limberg T, et al. Effects of pulmonary rehabilitation on physiologic and psychosocial outcomes in patients with chronic obstructive pulmonary disease. Ann Intern Med 1995;122:823-32.

23 Toshima MT, Blumberg E, Ries AL, et al. Does rehabilitation reduce depression in patients with chronic obstructive pulmonary disease? 7 Cardiopulm Rehabil 1992;12:261-9.

24 Engström CP, Persson LO, Larsson S, et al. Functional status and well-being in chronic obstructive pulmonary disease with regard to clinical parameters and smoking: a descriptive and comparative study. Thorax 1996;51:82530

25 Isoaho R, Keistinen T, Laippala P, et al. Chronic obstructive pulmonary disease and symptoms related to depression in elderly persons. Psychol Rep 1995;76:287-97.

26 McSweeny AJ, Grant I, Heaton RK, et al. Life quality of patients with chronic obstructive pulmonary disease. Arch Intern Med 1982;142:473-8.

27 Prigatano G, Wright E, Levin D. Quality of life and its predictors in patients with mild hypoxemia and chronic obstructive pulmonary disease. Arch Intern Med 1984;144: 1613-9.

28 Light RW, Merrill EJ, Despars JA, et al. Prevalence of depression and anxiety in patients with COPD. Relationship to functional capacity. Chest 1985;87:35-8.

29 Yellowlees PM. The treatment of psychiatric disorders in patients with chronic airways obstruction. Med 7 Aust 1987; 147:349-52.

30 Jones PW, Baveystock CM, Littlejohns P. Relationships between general health measured with the sickness impact profile and respiratory symptoms, physiological measures, and mood in patients with chronic airflow limitation. $A m$ Rev Respir Dis 1989;140:1538-43.

31 Gordon GH, Thiery MM, Mahutte $\mathrm{K}$, et al. Effect of desipramine on control of ventilation and depression scores in patients with severe chronic obstructive pulmonary disease. Psychiatry Res 1985;15:25-32.

32 Karajgi B, Rifkin A, Doddi S, et al. The prevalence of anxiety disorders in patients with chronic obstructive pulmonary disease. Am f Psychiatry 1990;147:200-1.

33 Spinhoven PH, Ormel J, Sloekers PPA, et al. A validation study of the Hospital Anxiety and Depression Scale (HADS) in different groups of Dutch subjects. Psychol Med 1997; 27:363-70.

34 Johnson G, Burvill PW, Anderson CS, et al. Screening instruments for depression and anxiety following stroke: experience in the Perth community stroke study. Acta Psychiatr Scand 1995;91:252-7.

35 Kessler RC, McGonagle KL, Zhao S, et al. Lifetime and 12 -month prevalence of DSM-III-R psychiatric disorders in the United States. Results from the national comorbidity survey. Arch Gen Psychiatry 1994;51:8-19.

36 Bijl RV, Van Zessen G, Ravelli A. Psychiatric morbidity among adults in the Netherlands: the NEMESIS study. II. Prevalence of psychiatric disorders (in Dutch). Ned Tijdschr Geneeskd 1997;141:2453-60.

37 Beckham EE, Leber WR, eds. Handbook of depression. 2nd ed. New York, London: The Guilford Press, 1995: 147-51.

38 Robertson MM, Katona CLE, eds. Depression and physical illness. Chichester: John Wiley \& Sons, 1997: 209-24, 30540, 391-406. 